\title{
ELECTROENCEPHALOGRAPHIC STUDIES IN CEREBRAL ANGIOMA
}

\section{P. ROSENBERG}

\author{
From the Department of Applied Electrophysiology, the National Hospital, Queen Square, London
}

An enquiry into the value of electroencephalography (E.E.G.) in cases of cerebral angioma was prompted by the need for accurate information with which to aid E.E.G. reporting. There are few references in the literature to which one can turn, and these are mainly isolated studies of cases of the Sturge-Weber syndrome.

In the present investigation a brief description of the clinical material used is followed by an analysis of the E.E.G. results. All figures given in percentages or years are changed to the nearest whole numbers for simplification.

\section{Technique}

Six-channel machines with amplifier performance complying with the E.E.G. Society recommendations (one Ediswan Mark 1, and two machines built in the National Hospital) were used in all cases. The scalp electrodes were of the pad variety, i.e. $1 \mathrm{~cm}$. diameter pads dipped in $5 \%$ saline and attached with silver screws to moulded perspex bases, as described by Grey Walter (1950). Nineteen electrodes were used in standard positions in antero-posterior or transverse great circle lines at a distance of 4 to $7 \mathrm{~cm}$. from one another, and were held attached to the scalp by a rubber harness fastened under the chin. Seven or eight standard positions were adopted in all cases and the recordings were bipolar without exception. Provocative techniques were used where indicated and overbreathing was done as a routine except where the condition of the patient rendered it inadvisable.

The routine time constant was 0.3 seconds and the high frequency response was $15 \%$ down at 75 cycles per second $(\mathrm{c} / \mathrm{s})$.

\section{Clinical Material}

The material comprised 55 consecutive cases of cerebral angioma proved by arteriography which were admitted to the National Hospital during the five and a half years from late 1946 to early 1952 . Cases suspected but not proved, and cases verified but not investigated by the E.E.G., were excluded from the series. Of the 55 cases, the pre-operative record of one was unsatisfactory while in two cases only the post-operative records were available. These three records were excluded from the analysis of results before operation. A total of 94 records was made.

\section{Clinical Analysis}

Of the 55 patients, 27 were male and 28 female. Their age composition is shown in Table $I$. The duration of symptoms before E.E.G. examination was on the average seven years. Brain (1951) states that a long history is common, and our figure shows an interesting comparison with that obtained in this laboratory for the duration of symptoms in cases of intracranial aneurysms which was approximately three years, and that for spontaneous subarachnoid haemorrhage which was roughly eight months before E.E.G. examination was carried out.

The angioma was right-sided in 25 cases, and in 30 was left-sided. Twenty-three were parietal, seven temporal, six occipital, seven frontal, five parieto-frontal, five parieto-temporal, one parietooccipital, and one occipito-temporal. Over half were supplied by the middle cerebral artery. The remainder were supplied, in order of frequency, by the anterior cerebral, posterior cerebral, and the vertebral arteries. Four involved the carotid syphon.

Thirty-six patients presented with epilepsy or developed fits during the course of the illness, a complication which is common, as Brain (1951) points out, while 17 had an associated mono- or hemi-paresis. Subarachnoid haemorrhage had occurred in 18 cases (with a further two doubtful ones). Cushing and Bailey (1928) and others do not mention what percentage of angiomata is complicated by haemorrhage but merely state that when subarachnoid bleeding supervenes death commonly results. The average age of patients with subarachnoid haemorrhage before examination was 34 years with a maximum incidence in the third and fourth decades. This age grouping is very similar to that of the whole series (Table I). In addition, it may be mentioned that only 13 patients complained of severe headache when seen. Twentyone had an audible intracranial bruit. In two patients the angiomata bled into the brain, and one of these died (both grade 3, see later). 
TABLE I

THE AGES OF THE 55 PATIENTS

\begin{tabular}{|c|c|c|c|c|}
\hline \multicolumn{2}{|c|}{ Age (in decades) } & Male & Female & Total (55) \\
\hline Second & $\cdots$ & 4 & 5 & 9 \\
\hline Third & $\ldots$ & 8 & 6 & 14 \\
\hline Fourth & $\cdots$ & 5 & 7 & 12 \\
\hline Fifth .. & $\cdots$ & 4 & 9 & 13 \\
\hline Sixth . . & $\cdots$ & 6 & 1 & 7 \\
\hline Average & & 31 years & 34 years & 32.5 years \\
\hline
\end{tabular}

Craniotomy was performed in 28 cases $(51 \%)$ where the angioma was superficial or partly so. In two of these the operation was terminated without any surgical interference with the angioma being attempted. The angioma was removed in 19 cases and its vessels ligated within the skull in seven. Four patients had the carotid artery on one or other side compressed under E.E.G. control before operation, three of these being included in the total of five patients whose carotid artery was later ligated. No E.E.G. changes were recorded in these cases during carotid compression for 20 minutes. The remaining 22 patients were considered to be unsuitable for operation. Two patients died after operation.

\section{E.E.G. Analysis}

The cases are divided into three groups according to the E.E.G. analysis (Table II). Group 1 includes normal or doubtfully abnormal records. Group 2 comprises those records showing mild unilateral abnormalities such as minor aysmmetries of amplitude or 4-7 c/s activity. Group 3 consists of records showing severe unilateral abnormalities, e.g. marked asymmetry between the two hemispheres, high voltage slow wave foci, or gross disorganization of the normal rhythms. These divisions are naturally somewhat arbitrary.

In Group 3 one case showed lateralizing, and one case localizing, features on the side of the brain

TABLE II

CLASSIFICATION OF CASES ACCORDING TO DEGREE OF E.E.G. ABNORMALITY IN 52 CASES OF ANGIOMA

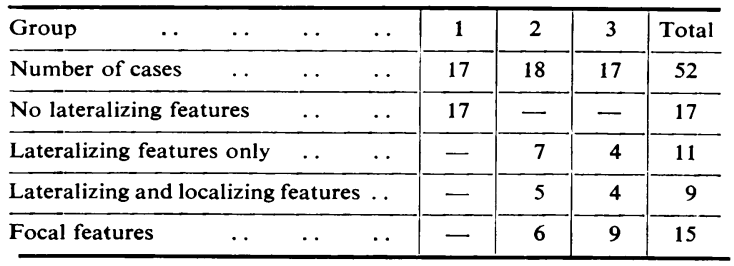

opposite to the angioma. A third, showing a high voltage slow wave focus, had an intracerebral haemorrhage in addition to the angioma. Two patients had an aneurysm as well as an angioma, the one having the record which was unsatisfactory, the other showing an E.E.G. grading (Table II) before operation of 2 (focal), and 13 months after operation of 2 (local). The E.E.G.s of another two patients when first recorded were normal, and during serial readings progressed to group 3 , one focal and one local. It may be of interest to add that one of the two patients last mentioned was examined five times before operation over the course of a year, the last four records showing a persistent slow wave focus in the left occipitotemporal area. As he suffered only from epilepsy and showed no physical signs, he was not admitted to hospital till he had been under observation for a year when an angioma was found in the position located by the E.E.G. Two other patients showed localized $8 \mathrm{c} / \mathrm{s}$ activity distinct from the normal alpha rhythm over the site of the lesion, both of which were in the left posterior parietal position.

Table II shows that out of 52 patients, 17 (33\%), i.e. Group 1, give normal or doubtfully abnormal records, while the E.E.G.s of the other 35 cases $(67 \%)$ show lateralizing or localizing features. This last figure may be compared to an approximate one of $37 \%$ for intracranial aneurysms found in this laboratory when similar criteria are used.

A more detailed analysis of the E.E.G. findings before operation shows that alpha $(8-13 \mathrm{c} / \mathrm{s})$ activity is completely absent in three records, is present on one side only in four, and is asymmetrical in 17. The voltage is lower on the same side as the lesion in 13, and is greater on the same side in four, there being no apparent reason for this difference. Theta $(4-7 \mathrm{c} / \mathrm{s})$ activity is present in 34 records, mostly non-focal, usually irregular and confined to the side of the lesion, and predominantly at $6-7 \mathrm{c} / \mathrm{s}$. The voltage is mostly low. Delta $\left(\frac{1}{2}-3 \frac{1}{2} \mathrm{c} / \mathrm{s}\right)$ activity is present in 23 records, mostly focal and of moderate to high voltage, and usually at $2-3 \mathrm{c} / \mathrm{s}$. Beta (14-30 c/s) activity is seen in the records of 13 patients, mostly small in amount and frontal and bilateral, sometimes spread over the whole cortex, and unilateral in one case over the site of the lesion. Eleven of these patients suffered from epilepsy, and the remaining two were not receiving medication.

A composite picture might therefore show a low to moderate voltage alpha rhythm, possibly asymmetrical, irregular 6-7 c/s activity on the side of the lesion, fairly localized, with perhaps a high voltage delta focus on the same side as well. 
Post-operative records of eight patients were available, of whom six were examined before operation. The angioma was removed in five cases and its vessels ligated in one. Two patients had the internal or common carotid artery on one side ligated. Two patients within the six weeks after operation showed a more abnormal E.E.G. than before. All records up to seven years after operation were still abnormal, the E.E.G. gradings being almost unchanged as compared with those taken before operation, both for craniotomy and carotid ligation, with the possible exception that the abnormal slow activity was less strictly localized. On the other hand, no definite correlation between the clinical state and the E.E.G. state was found, as six of the eight patients showed clinical improvement, a finding not supported by the E.E.G.

When the E.E.G. abnormality is correlated with age and the duration of symptoms before E.E.G. examination it is seen that with decreasing age and duration of symptoms the E.E.G. is progressively more abnormal (Table III). This general trend is seen in other disorders. Fits have little bearing on

TABLE III

CORRELATION OF E.E.G. ABNORMALITY WITH AGE AND DURATION OF SYMPTOMS AT TIME OF E.E.G. EXAMINATION

\begin{tabular}{|c|c|c|c|c|c|}
\hline \multicolumn{3}{|c|}{ E.E.G. grading (see Table II) } & \multirow{2}{*}{$\begin{array}{c}1 \\
17 \\
\end{array}$} & \multirow{2}{*}{$\frac{2}{18}$} & \multirow{2}{*}{$\begin{array}{r}3 \\
17 \\
\end{array}$} \\
\hline Number of cases & .. & . & & & \\
\hline Average age (years) & .. & .. & 37 & 30 & 30 \\
\hline Duration of symptom & ns (ye & & 11 & 6 & 4 \\
\hline
\end{tabular}

these E.E.G. changes, as of the 34 patients with records taken before operation and giving a history of epilepsy, only four showed definite epileptic activity (spikes) on their records, with a further six showing doubtful dysrrhythmic activity. These last 10 patients are distributed fairly evenly among the three E.E.G. groups. (As nearly all the 34 patients are on anticonvulsant therapy, fast activity is not considered here as an epileptic manifestation.)

Subarachnoid haemorrhage too occurs almost equally among the three E.E.G. groups (five, eight, and five cases respectively), but it is of interest to find that when 18 cases of angioma with subarachnoid haemorrhage, taken from this series, are compared with the series as a whole, the percentage of E.E.G. lateralizing abnormality rises slightly from $\mathbf{6 7}$ for the whole to $\mathbf{7 2}$ for the selected group.

An equivalent group of 18 cases of subarachnoid haemorrhage derived from confirmed cerebral aneurysm gives lateralizing E.E.G. abnormalities in
$50 \%$ of the cases. This suggests that a case of subarachnoid haemorrhage showing E.E.G. lateralizing abnormality is more likely to be due to an underlying angioma than to an aneurysm, though this obviously does not apply to the individual case.

It is known (e.g., Roseman, Bloor, and Schmidt, 1951) that the sooner after a subarachnoid haemorrhage the E.E.G. is taken, the greater is the likelihood of its being abnormal. Conversely, should the patient live and not have an intracerebral haematoma, the E.E.G. improves with time.

\section{Discussion}

Broager and Hertz (1949), using the bipolar method on one patient, found a left-sided parasagittal premotor focus with constant phase reversal before operation, and diffuse slow activity 'one week after operation. Raskin (1949) described-slowing of 7-8 c/s activity in all leads in another. Radermecker (1951) reviewed nine patients with facial naevi, six of whom had calcified cerebral lesions. The E.E.G. findings in this group did not show any common pattern. Other cases are described by Cornil, Paillas, and Gastaut (1949), by Monnier and Mutrux (1949), and by Craig (1949). Larmande (1948) quotes Green's description of an infant with epilepsy who showed high voltage $2 \frac{1}{2}-6 \mathrm{c} / \mathrm{s}$ activity with an area of non-activity over the region of the angioma. Gastaut and Bonnal (1952) describe a case of angioma in the right temporal lobe, confirmed by arteriography, with focal $2 \frac{1}{2} \mathrm{c} / \mathrm{s}$ waves over the site of the lesion.

The relation of the E.E.G. abnormality to the time factor in cases of subarachnoid haemorrhage, irrespective of the underlying pathology, is stressed by Greenstein and Strauss (1946) and by Roseman, Bloor, and Schmidt (1951). Bailey (1948) points out that though epilepsy is commonly associated with angioma it is in no way specific, and in this series E.E.G. confirmation of epilepsy was obtained in only a small proportion of those patients giving a history of it. The association of epilepsy with fast activity on the records in this series cannot be assessed accurately as most of the patients suffering from epilepsy are taking barbiturates.

Two patients show progressively deteriorating records with advancing clinical changes. Another two show more severe E.E.G. abnormalities within six weeks of operation than before. This is in agreement with other forms of pathology. But no correlation is found between the post-operative clinical and post-operative E.E.G. states. It is not known what significance to attach to the two records where localized $8 \mathrm{c} / \mathrm{s}$ activity is found over the site of the lesion. 
In the few cases where carotid compression on the appropriate side was done under E.E.G. control before operation no electrical changes were recorded. The same negative result was obtained in the majority of cases of a much larger group of intracranial aneurysms tested in this laboratory in the same way.

The left ventricle of the heart of one patient in the series was found to be enlarged, though no cardiac disease or hypertension could be demonstrated. This raised the possibility that the angioma was causing an abnormal circulatory state sufficient to produce the cardiac enlargement. From an analysis of samples of blood taken from the patient's heart and internal jugular vein it was estimated that the cardiac output was increased by $40 \%$ (7.2 litres per minute) above the normal for the patient $(5 \cdot 1$ litres per minute), and that the circulation through the brain was approximately doubled, giving an arteriovenous shunt of the order of one litre per minute. Gibbs, Maxwell, and Gibbs (1947) state that the average resting blood flow in the brains of seven patients (not suffering from angioma) is $617 \mathrm{ml}$. per minute.

To sum up, no specific E.E.G. disturbance diagnostic of angioma could be seen in the 94 records of the 55 patients. In general, an angioma gives a similar E.E.G. picture to that of cerebral tumour which characteristically shows localized high voltage irregular delta waves. However, the impression is that with angioma raised intracranial pressure and the spread of oedema play on the whole a lesser part than in cases of tumour, giving less generalized delta activity that will obscure a true focus, and allowing a clearer localization of the intermediate slow activity. The same distinction serves to differentiate angioma from cerebral abscess, where in addition, the slow delta waves at $\frac{1}{2}-2 \mathrm{c} / \mathrm{s}$ are usual. But as Cobb (1950) points out, the determination of pathology by the E.E.G. is at the most, uncertain.

\section{Summary}

The electroencephalograms of 55 cases of proved cerebral angioma have been analysed.

The E.E.G. gives a lateralizing or localizing indication in $67 \%$ of the cases, the usual findings being localized $6-7 \mathrm{c} / \mathrm{s}$ activity and/or high voltage 2-3 c/s waves showing phase reversal over the site of the lesion. These changes, with minor variations, are usually seen with other forms of cerebral tumour.

The value of electroencephalography as a diagnostic aid in angioma is discussed.

I am indebted to Dr. W. A. Cobb for his advice and criticism in the preparation of this paper, and to the physicians and surgeons of the National Hospital for access to their case records.

\section{REFERENCES}

Bailey, P. (1948). Intracranial Tumors, 2nd ed. Springfield, IIl. Brain, W. Russell (1951). Diseases of the Nervous System, 4th ed. London.

Broager, B., and Hertz, H. (1949). Acta Psychiat., Kbh., 24, 1

Cobb, W. A. (1950). In Electroencephalography, edited by Hill, J. D. N., and Parr, G. London.

Cornil, G., Paillas, J., and Gastaut, H. (1949). Ann. méd.-psychol., 107, (II), 474 .

Craig, J. M. (1949). J. Neuropath., 8, 305.

Cushing, H., and Bailey, P. (1928). Tumors Arising from the BloodVessels of the Brain. Springfield, III.

Gastaut, H., and Bonnal, J. (1952). Electroenceph. clin. Neurophysiol., 4, 97.

Gibbs, F. A., Maxwell, H., and Gibbs, E. L. (1947). Arch. Neurol. Psychiat., Chicago, 57, 137.

Greenstein, L., and Strauss, H. (1946). J. Mt Sinai Hosp., 13, 76. Larmande, A. M. (1948). La Neuro-angiomatose encéphalo-faciale, Paris.

Monnier, M., and Mutrux, G. (1949). Ann. méd.-psychol., 107, (II), 340 .

Radermecker, J. (1951). Acta neurol. psychiat. belg., 51, 427.

Raskin, N. (1949). J. Neuropath., 8, 326.

Roseman, E., Bloor B. M., and Schmidt, R. P. (1951). Neurology,

Walter, W. G. (1950). In Electroencephalography, edited by Hill and Parr, London. 